Case Report

\title{
Actinomyces naeslundii: An Uncommon Cause of Endocarditis
}

\author{
Christopher D. Cortes, ${ }^{1}$ Carl Urban, ${ }^{1,2}$ and Glenn Turett ${ }^{1}$ \\ ${ }^{1}$ The Dr. James J. Rahal, Jr. Division of Infectious Diseases, NewYork-Presbyterian Queens, Flushing, NY 11355, USA \\ ${ }^{2}$ Department of Medicine, Weill Cornell Medical College, New York, NY 10065, USA
}

Correspondence should be addressed to Carl Urban; cmurban@nyp.org and Glenn Turett; gst9001@nyp.org

Received 21 September 2015; Accepted 16 November 2015

Academic Editor: Sandeep Dogra

Copyright (C) 2015 Christopher D. Cortes et al. This is an open access article distributed under the Creative Commons Attribution License, which permits unrestricted use, distribution, and reproduction in any medium, provided the original work is properly cited.

Actinomyces rarely causes endocarditis with 25 well-described cases reported in the literature in the past 75 years. We present a case of prosthetic valve endocarditis (PVE) caused by Actinomyces naeslundii. To our knowledge, this is the first report in the literature of endocarditis due to this organism and the second report of PVE caused by Actinomyces.

\section{Introduction}

Actinomyces naeslundii is a Gram positive anaerobic bacillary commensal of the human oral cavity. Septicemia with this organism is uncommon and poses an increased risk of subacute and chronic granulomatous inflammation, which can affect all organ systems via hematogenous spread [1]. We discuss a rare case of endocarditis caused by this organism.

\section{Case Presentation}

A 51-year-old Hispanic woman, with a history of hypothyroidism, asthma, and aortic stenosis requiring a bioprosthetic aortic valve replacement, presented with fever, nausea, and a 23-pound weight loss over the prior two months. The valve was excised at another hospital prior to patient's presentation to us and no pathology information was available. She also complained of diffuse myalgias, erythematous lesions over the arms and legs, and clouded vision. One month prior to aortic valve replacement, she had dental implants inserted. Her symptoms began two months after valve replacement surgery. Physical examination on presentation was notable for a febrile $\left(T_{\text {MAX }}=103.1 \mathrm{~F}\right)$ woman in mild distress, but hemodynamically stable. Pertinent findings included poor dentition with apparent tooth decay and fracture below the gum line of two adjacent teeth, small punctate lesions over her upper and lower extremities, Roth spots on ophthalmoscopic exam, a well-healed sternotomy scar, and a grade III/VI holosystolic decrescendo murmur. Abnormal laboratory tests included a WBC count of $16.5 \mathrm{~K} / \mu \mathrm{L}$ (reference range: $4.8-$ $10.8 \mathrm{~K} / \mu \mathrm{L}$ ) with $88.5 \%$ neutrophils and C-reactive protein (CRP) $7.02 \mathrm{mg} / \mathrm{L}$ (reference range: $0.03-0.49 \mathrm{mg} / \mathrm{dL}$ ). Only one set of blood cultures was drawn prior to empirically starting vancomycin and ceftriaxone (the patient had a vague history of a nonlife threatening penicillin allergy). The aerobic bottle showed bacterial growth at 26.3 hours and in the anaerobic bottle at 57.1 hours. They were subsequently inoculated on anaerobic blood agar and Brucella Laked Blood Agar with Kanamycin and Vancomycin (LKV). The isolate was identified as Actinomyces naeslundii by VITEK 2 ANC ID Card (BioMerieux) anaerobic and corynebacterium identification. Vancomycin was discontinued and ceftriaxone alone was used.

A transesophageal echocardiogram demonstrated trace mitral and tricuspid valve regurgitation, but no definitive vegetation. Repeat blood cultures drawn on day two of admission showed no growth and she defervesced within two days. After 7 days of treatment, her leukocytosis resolved and she was no longer symptomatic. No posttreatment echo was done seeing pretreatment and 10 days into treatment, studies showed no aortic valve dehiscence or regurgitation.

A CRP repeated after 21 days was $0.8 \mathrm{mg} / \mathrm{L}$. Four weeks into therapy, ceftriaxone was changed to ertapenem due to a febrile reaction attributed to ceftriaxone. The patient received a total of sixteen weeks of appropriate intravenous antibiotic therapy. She was evaluated by an allergy/immunology 
TABLE 1: Case reports of endocarditis caused by Actinomyces species.

\begin{tabular}{|c|c|c|c|c|c|c|}
\hline Reference & Age/sex & Organism & Valve & Surgery & Therapy & Outcome \\
\hline Uhr, 1939 [10] & $24 \mathrm{M}$ & Actinomyces bovis & Aortic/Mitral & No & Sulfathiazole & Dead \\
\hline $\begin{array}{l}\text { Beamer et al., } \\
1945[5]\end{array}$ & $55 \mathrm{M}$ & Actinomyces sp. & Aortic/Mitral & No & None & Dead \\
\hline $\begin{array}{l}\text { Blevins and Mac } \\
\text { Neal, } 1946 \text { [23] }\end{array}$ & UK & Actinomyces septicus & Mitral & No & None & UK \\
\hline $\begin{array}{l}\text { MacNeal et al., } \\
1946 \text { [6] }\end{array}$ & $39 \mathrm{M}$ & Actinomyces sp. & Mitral & No & $\mathrm{PCN}$ & Alive \\
\hline $\begin{array}{l}\text { Wedding, } 1947 \\
\text { [7] }\end{array}$ & $37 \mathrm{M}$ & Actinomyces sp. & Mitral & No & Sulfathiazole & Dead \\
\hline $\begin{array}{l}\text { Wedding, } 1947 \\
\text { [7] }\end{array}$ & $71 \mathrm{~F}$ & Actinomyces sp. & Aortic & No & None & Dead \\
\hline $\begin{array}{l}\text { Stokes et al., } 1951 \\
\text { [24] }\end{array}$ & $27 \mathrm{~F}$ & Actinomyces muris & Mitral & No & Chloramphenicol & Alive \\
\hline $\begin{array}{l}\text { Walters et al., } \\
1962 \text { [11] }\end{array}$ & $43 \mathrm{~F}$ & Actinomyces bovis & Aortic/Mitral & No & $\mathrm{PCN}$ & Alive \\
\hline $\begin{array}{l}\text { Dutton and } \\
\text { Inclan, } 1968 \text { [18] }\end{array}$ & $6 \mathrm{M}$ & Actinomyces israelii & Mitral & No & $\mathrm{PCN}$ & Dead \\
\hline $\begin{array}{l}\text { Gutschik, } 1976 \\
{[12]}\end{array}$ & $70 \mathrm{M}$ & Actinomyces viscosus & Mitral & No & PCN & Alive \\
\hline $\begin{array}{l}\text { Lam et al., } 1993 \\
\text { [19] }\end{array}$ & $65 \mathrm{M}$ & Actinomyces israelii & Aortic/Mitral & No & $\mathrm{PCN}$ & Alive \\
\hline $\begin{array}{l}\text { Moffatt et al., } \\
1996 \text { [16] }\end{array}$ & $48 \mathrm{M}$ & Actinomyces meyeri & Aortic & Yes, AVR & $\mathrm{PCN}$ & Alive \\
\hline $\begin{array}{l}\text { Reddy et al., } \\
1997 \text { [25] }\end{array}$ & $64 \mathrm{M}$ & Actinomyces pyogenes & Aortic & No & Multiple & Dead \\
\hline $\begin{array}{l}\text { Hamed, } 1998 \\
{[13]}\end{array}$ & $81 \mathrm{M}$ & Actinomyces viscosus & Aortic & No & Ceftizoxime & Alive \\
\hline $\begin{array}{l}\text { Huang et al., } \\
1998 \text { [17] }\end{array}$ & $55 \mathrm{M}$ & Actinomyces meyeri & Mitral & No & Ampicillin-sulbactam & Alive \\
\hline $\begin{array}{l}\text { Mardis and } \\
\text { Many Jr., } 2001 \\
{[14]}\end{array}$ & $38 \mathrm{M}$ & Actinomyces viscosus & Mitral & No & Multiple, $\mathrm{PCN}$ & Alive \\
\hline $\begin{array}{l}\text { Westling et al., } \\
2002 \text { [26] }\end{array}$ & $40 \mathrm{~F}$ & Actinomyces funkei & Tricuspid & No & Multiple & Alive \\
\hline $\begin{array}{l}\text { Oh et al., } 2005 \\
{[27]}\end{array}$ & $33 \mathrm{M}$ & Actinomyces odontolyticus & Tricuspid & No & Ceftriaxone (CTX) & Alive \\
\hline $\begin{array}{l}\text { Julian et al., } \\
2005 \text { [15] }\end{array}$ & $43 \mathrm{~F}$ & Actinomyces viscosus & Aortic & Yes, AVR & Amp, CTX, and vancomycin & Alive \\
\hline $\begin{array}{l}\text { Cohen et al., } \\
2007 \text { [21] }\end{array}$ & $68 \mathrm{M}$ & Actinomyces neuii & Aortic & Yes, AVR & Amp, CTX, and gentamicin & Alive \\
\hline $\begin{array}{l}\text { Oddó and } \\
\text { Ayala, } 2007 \text { [8] }\end{array}$ & $34 \mathrm{M}$ & Actinomyces sp. & Mitral & No & UK & Dead \\
\hline $\begin{array}{l}\text { Grundmann et } \\
\text { al., } 2010 \text { [22] }\end{array}$ & $66 \mathrm{M}$ & Actinomyces neuii & Aortic (prosthetic) & No & $\mathrm{PCN}$ & Alive \\
\hline $\begin{array}{l}\text { Adalja and } \\
\text { Vergis, } 2010 \text { [20] }\end{array}$ & $87 \mathrm{M}$ & Actinomyces israelii & Mitral & No & PCN & Alive \\
\hline $\begin{array}{l}\text { Mehrzad et al., } \\
2013 \text { [9] }\end{array}$ & $49 \mathrm{M}$ & Actinomyces sp. & Tricuspid & No & Multiple & Alive \\
\hline $\begin{array}{l}\text { Kottam et al., } \\
2015 \text { [28] }\end{array}$ & $30 \mathrm{~F}$ & Actinomyces turicensis & Eustachian & No & Multiple, pen, and CTX & Alive \\
\hline Present Report & $51 \mathrm{~F}$ & Actinomyces naeslundii & Aortic (prosthetic) & No & Vanco, CTX, ertapenem, and amoxicillin & Alive \\
\hline
\end{tabular}


specialist and was cleared to receive amoxicillin which then was started at a dose of 1 gram every 12 hours for a planned twelve-month total course of antibiotics. The patient also had her tooth extracted after discharge from the hospital and she follows up every six months with her dentist. Eight weeks later, she presented to the clinic for follow-up. She was well compliant with and tolerating amoxicillin. Surveillance blood cultures drawn then were sterile. Two weeks after completion of the twelve months of antibiotics, she remained well and surveillance cultures drawn on that visit remained negative.

\section{Discussion}

We present an unusual case of Actinomyces naeslundii endocarditis in an immunocompetent individual. According to the modified Duke's criteria, our patient had 4 minor criteria classifying her condition as possible endocarditis. The likelihood of endocarditis was strengthened by recent dental work followed by aortic valve replacement surgery and ongoing poor dentation; persistent fevers two months after surgery; bacteremia with Actinomyces naeslundii, which is associated with early caries and tooth decay [2]; significant weight loss; evidence of immunologic sequelae (Roth spots) and an elevated inflammatory marker (CRP). Respecting the possibility of prosthetic valve endocarditis prompted aggressive treatment with an extended course of parenteral followed by oral antibiotics.

Actinomyces bacteremia is well described in the dental literature following dental procedures [3]. However, Actinomyces species rarely cause endocarditis. Actinomycosis is more commonly associated with cervicofacial, pelvic, and thoracic deep-seated infections. There is no specific recommended duration of therapy for Actinomyces endocarditis. For patients with deep-seated thoracic infections, 2 to 6 weeks of intravenous antibiotics are advised, followed by oral penicillins for six to twelve months [4].

An extensive review of the literature since 1939 revealed 24 well-described cases of endocarditis due to Actinomyces including six cases of Actinomyces species [5-9], two of Actinomyces bovis $[10,11]$, four of Actinomyces viscosus [1215], two cases of Actinomyces meyeri [16, 17], three of Actinomyces israelii [18-20], two of Actinomyces neuii [21, 22], and one of each of Actinomyces septicus [23], Actinomyces muris [24], Actinomyces pyogenes [25], Actinomyces funkei [26], and Actinomyces odontolyticus [27] (Table 1). Almost half of these patients were noted to have predisposing cardiac pathology. One recent report described a case of eustachian valve endocarditis caused by Actinomyces turicensis [28]. Four of the 20 patients who received therapy died from pulmonary edema and acute respiratory failure. Three patients underwent aortic valve replacement surgery and survived. Most of the patients received a beta-lactam antibiotic (mainly penicillin), but few received other classes of antibiotics (glycopeptide, sulfonamide, aminoglycoside, and chloramphenicol). In 15 patients, duration of antibiotic therapy was stated and ranged from 24 days to 13 months (mean 21.4 weeks, median 16 weeks).

To our knowledge, this is the first case of Actinomyces naeslundii endocarditis reported in the literature to date and the second of prosthetic valve endocarditis caused by Actinomyces [22]. Grundmann et al. described a case of Actinomyces neuii prosthetic valve endocarditis also managed successfully with medical treatment alone (6-week intravenous regimen of penicillin followed by oral amoxicillin for 11 months) [22].

Similar to the treatment of other serious Actinomyces infections, endocarditis requires several weeks of intravenous antibiotic therapy, followed by six to twelve months of oral therapy. High doses of penicillin, for a prolonged period of time, remain the therapy of choice [29].

\section{Conflict of Interests}

All authors report no conflict of interests.

\section{Authors' Contribution}

All authors contributed equally to this work.

\section{References}

[1] S. Abozaid, A. Peretz, W. Nasser, and Y. Zarfin, "Rare infection-prolonged A. naeslundii bacteremia caused by severe caries," Harefuah, vol. 152, no. 7, pp. 379-435, 2013.

[2] J. A. Aas, B. J. Paster, L. N. Stokes, I. Olsen, and F. E. Dewhirst, "Defining the normal bacterial flora of the oral cavity," Journal of Clinical Microbiology, vol. 43, no. 11, pp. 5721-5732, 2005.

[3] F. K. Bahrani-Mougeot, B. J. Paster, S. Coleman, J. Ashar, S. Barbuto, and P. B. Lockhart, "Diverse and novel oral bacterial species in blood following dental procedures," Journal of Clinical Microbiology, vol. 46, no. 6, pp. 2129-2132, 2008.

[4] J. Choi, W.-J. Koh, T. S. Kim et al., "Optimal duration of IV and oral antibiotics in the treatment of thoracic actinomycosis," Chest, vol. 128, no. 4, pp. 2211-2217, 2005.

[5] P. R. Beamer, E. H. Reinhard, and I. I. Goodof, "Vegetative endocarditis caused by higher bacteria and fungi: review of previous cases and report of two cases with autopsies," American Heart Journal, vol. 29, no. 1, pp. 99-112, 1945.

[6] W. J. MacNeal, A. Blevins, and A. W. Duryee, "Clinical arrest of endocardial actionomycosis after forty-four million units of penicillin," American Heart Journal, vol. 31, no. 6, pp. 668-676, 1946.

[7] E. S. Wedding, "Actinomycotic endocarditis: report of two cases with a review of the literature," Archives of Internal Medicine, vol. 79, no. 2, pp. 203-227, 1947.

[8] B. D. Oddó and R. F. Ayala, "Actinomycotic infective endocarditis of the mitral valve. Anatomoclinical case and review of literature," Revista Chilena de Infectología, vol. 24, no. 3, pp. 232235, 2007.

[9] R. Mehrzad, M. Sublette, and M. Barza, "Polymicrobial endocarditis in intravenous heroin and fentanyl abuse," Journal of Clinical and Diagnostic Research, vol. 7, no. 12, pp. 2981-2985, 2013.

[10] N. Uhr, "Bacterial endocarditis: report of a case in which the cause was Actinomyces bovis," Archives of Internal Medicine, vol. 64, no. 1, pp. 84-90, 1939.

[11] E. W. Walters, M. J. Romansky, A. C. Johnson, and S. J. Conway, "Actinomyces bovis endocarditis: an uncommon and complex problem," Antimicrobial Agents and Chemotherapy, vol. 2, no. 5, pp. 517-525, 1962. 
[12] E. Gutschik, "Endocarditis caused by Actinomyces viscosus," Scandinavian Journal of Infectious Diseases, vol. 8, no. 4, pp. 271274, 1976.

[13] K. A. Hamed, "Successful treatment of primary Actinomyces viscosus endocarditis with third-generation cephalosporins," Clinical Infectious Diseases, vol. 26, no. 1, pp. 211-212, 1998.

[14] J. S. Mardis and W. J. Many Jr., "Endocarditis due to Actinomyces viscosus," Southern Medical Journal, vol. 94, no. 2, pp. 240-243, 2001.

[15] K. G. Julian, L. de Flesco, L. E. Clarke, and L. J. Parent, “Actinomyces viscosus endocarditis requiring aortic valve replacement," Journal of Infection, vol. 50, no. 4, pp. 359-362, 2005.

[16] S. Moffatt, A. R. Ahmen, and K. Forward, "First reported case of bacterial endocarditis attributable to Actinomyces meyeri," Canadian Journal of Infectious Diseases, vol. 7, no. 1, pp. 71-73, 1996.

[17] K.-L. Huang, S. M. Beutler, and C. Wang, "Endocarditis due to Actinomyces meyeri," Clinical Infectious Diseases, vol. 27, no. 4, pp. 909-910, 1998.

[18] W. P. Dutton and P. Inclan, "Cardiac actinomycosis," Diseases of the Chest, vol. 54, no. 5, pp. 463-467, 1968.

[19] S. Lam, J. Samraj, S. Rahman, and E. Hilton, "Primary actinomycotic endocarditis: case report and review," Clinical Infectious Diseases, vol. 16, no. 4, pp. 481-485, 1993.

[20] A. A. Adalja and E. N. Vergis, "Actinomyces israelii endocarditis misidentified as 'Diptheroids", Anaerobe, vol. 16, no. 4, pp. 472473, 2010.

[21] E. Cohen, J. Bishara, B. Medalion, A. Sagie, and M. Garty, "Infective endocarditis due to Actinomyces neuii," Scandinavian Journal of Infectious Diseases, vol. 39, no. 2, pp. 180-183, 2007.

[22] S. Grundmann, J. Huebner, J. Stuplich et al., "Prosthetic valve endocarditis due to Actinomyces neuii successfully treated with antibiotic therapy," Journal of Clinical Microbiology, vol. 48, no. 3, pp. 1008-1011, 2010.

[23] A. Blevins and W. J. Mac Neal, "Actinomyces septicus from human endocarditis," American Heart Journal, vol. 31, no. 6, pp. 663-667, 1946.

[24] J. F. Stokes, I. R. Gray, and E. J. Stokes, “Actinomyces muris endocarditis treated. with chloramphenicol," British Heart Journal, vol. 13, no. 2, pp. 247-251, 1951.

[25] I. Reddy, D. A. Ferguson Jr., and F. A. Sarubbi, "Endocarditis due to Actinomyces pyogenes," Clinical Infectious Diseases, vol. 25, no. 6, pp. 1476-1477, 1997.

[26] K. Westling, C. Lidman, and A. Thalme, "Tricuspid valve endocarditis caused by a new species of actinomyces: Actinomyces funkei," Scandinavian Journal of Infectious Diseases, vol. 34, no. 3, pp. 206-207, 2002.

[27] S. Oh, P. R. Havlen, and N. Hussain, "A case of polymicrobial endocarditis due to anaerobic organisms in an injection drug user," Journal of General Internal Medicine, vol. 20, no. 10, pp. C1-C2, 2005.

[28] A. Kottam, R. Kaur, D. Bhandare et al., "Actinomycotic endocarditis of the eustachian valve: a rare case and a review of the literature," Texas Heart Institute Journal, vol. 42, no. 1, pp. 44-49, 2015.

[29] T. A. Russo, "Agents of actinomycosis," in Bennetts Principles and Practices of Infectious Diseases, J. E. Mandell, R. Douglas, and M. J. Blaser, Eds., Elsevier Saunders, Philadelphia, Pa, USA, 8th edition, 2015. 


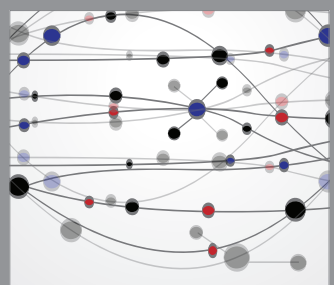

The Scientific World Journal
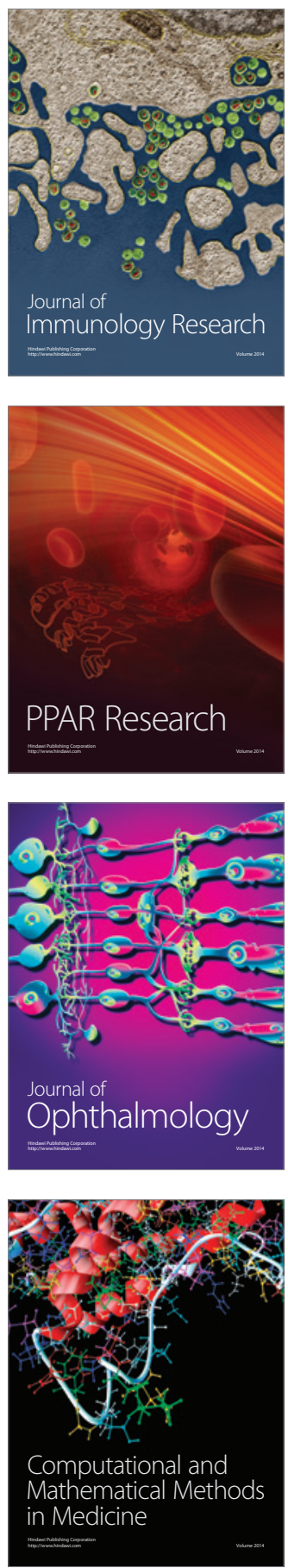

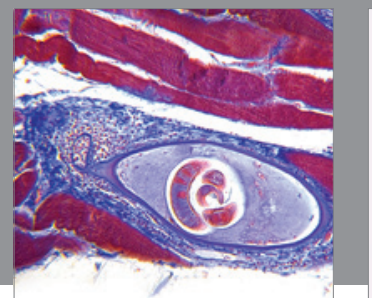

Gastroenterology

Research and Practice
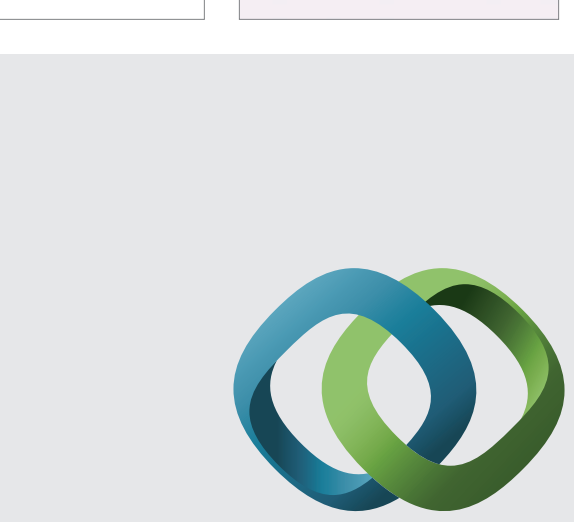

\section{Hindawi}

Submit your manuscripts at

http://www.hindawi.com
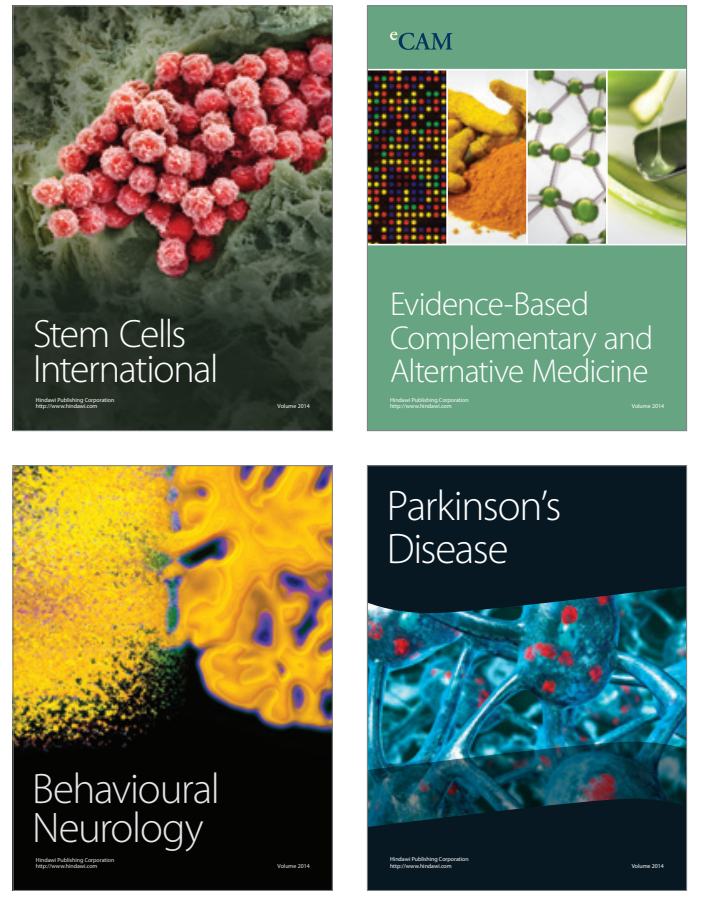
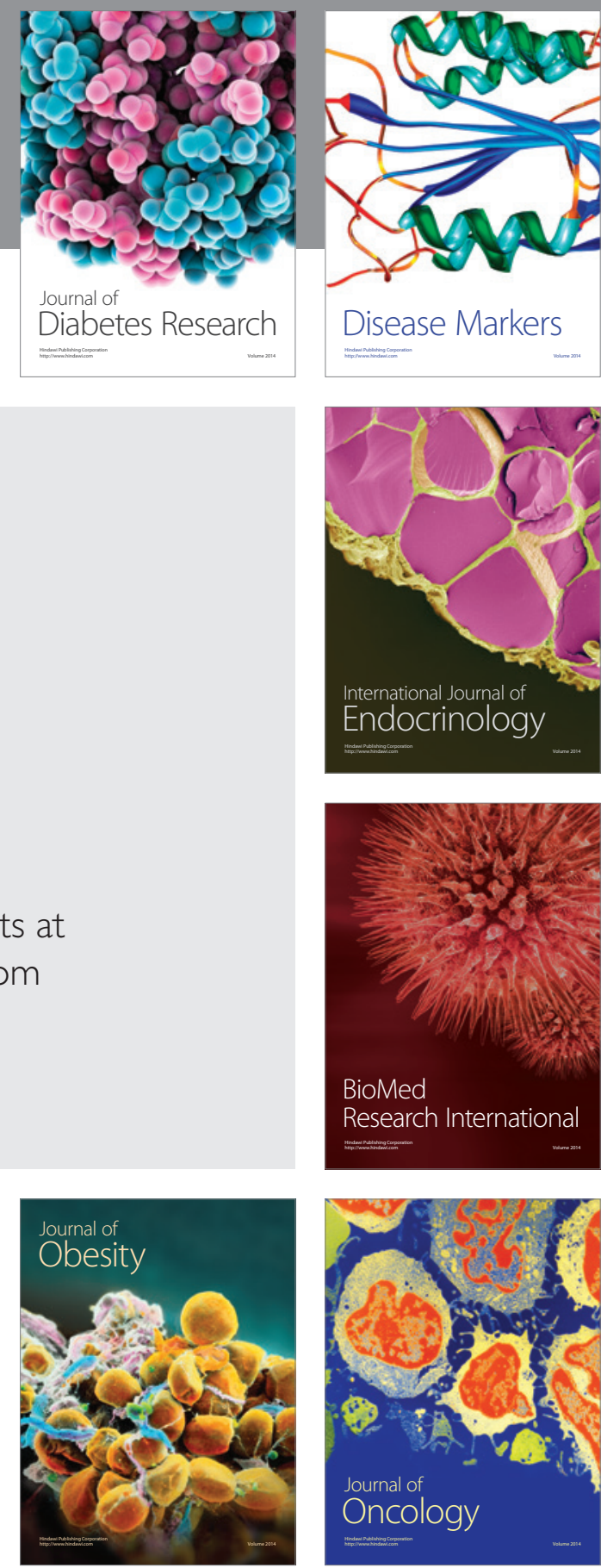

Disease Markers
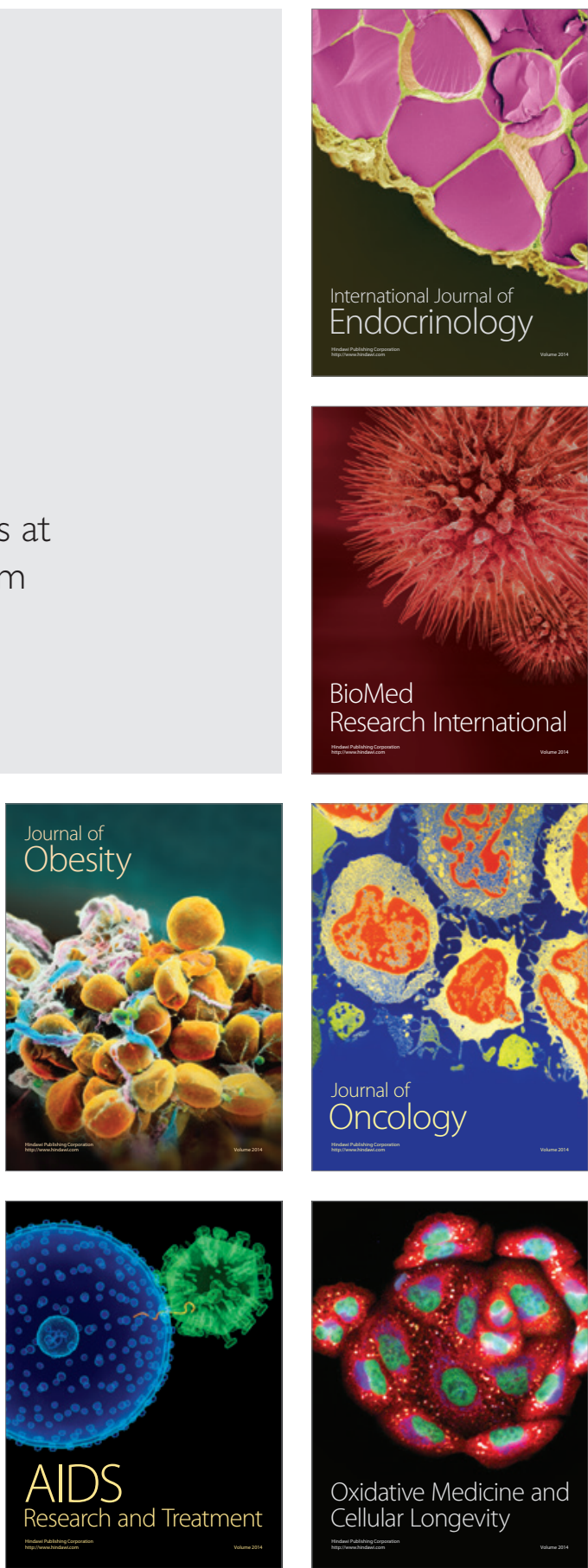